\title{
Living Precarious Lives? Time and Temporality in Visual Arts Careers
}

\author{
By Paula Serafini \& Mark Banks
}

\begin{abstract}
Although precarity has always been a characteristic feature of artistic labour, many critics now claim it is becoming more widespread and engrained. However, while the idea of precarity offers a good descriptor of the conditions of artistic labour, it also has its limits. Firstly, it tends to gloss over social differences in the distribution of precariousness. And secondly, precarity tends to imply a universal condition of 'temporal poverty' where all social experience appears dominated by the frenetic demands of a speeded-up, unstable and fragmented social world. In this article, we show how these two omissions are interlinked and prevent a more nuanced understanding of time in artistic labour. Drawing from findings from empirical research with working visual artists in the Midlands of the UK, we propose three schematic ways of thinking about the organisation of time and temporality in routine artistic practice. We name these three temporal contexts 'the artistic career'; 'the time of making art' and 'the temporality of the work'. By researching how artists might be differently positioned in relation to time, we suggest, we not only obtain a more precise understanding of how professional artists' lives are organised, managed and lived, but also a more distinct understanding of precarity itself.
\end{abstract}

Keywords: Precarity, time, temporality, artistic work, careers, creative labour.

Serafini, Paula and Mark Banks "Living Precarious Lives? Time and Temporality in Visual Arts Careers", Culture Unbound, Volume 12, Issue 2, 2020:351-372. Published by Linköping University Electronic Press: http://www.cultureunbound.ep.liu.se 


\section{Introduction}

In the last decades, 'precarity' has emerged as a key concept applied to the analysis of labour politics and the contemporary workplace (Hewison 2016, Kalleberg 2009, Neilson \& Rossiter 2005, Prosser 2016, Standing 2011, Vosko 2000). Precarious work is generally defined as work which exhibits various combinations of "uncertainty, instability, vulnerability and insecurity" (Hewison 2016: 428), and the 'precariat' have been famously identified as a putatively new class of workers united by their lack of 'labour-related security' (Standing 2011: 10), including low wages, intermittent work and weakened workplace protections. While applicable to most forms of work, precarity has now become strongly associated with the kinds of artistic work undertaken within the creative and cultural industries (Bain \& MacLean 2013, Banks, Gill \& Taylor 2013, de Peuter 2014, Gill \& Pratt 2008, Lindström 2016, Mahon et al 2018). Typically, precarious artistic work is seen to rely on short-term, project-based endeavours, often undertaken by solo, freelancing individuals, contractors or small teams, who convene to fulfil creative briefs or commissions before dispersing and moving on to the next task or assignment (Eikhof \& Warhurst 2013, Mahon et al 2018). While pay and rewards can sometimes be high, more often they tend to be low, and are frequently irregular, intermittent or unevenly distributed (Banks 2017, Gerber 2017, Lingo \& Tepper 2013). In general terms therefore, precarious artistic work tends to be characterised by a high degree of 'uncertainty' (Pasquinelli \& Sjöholm 2015, 75), yet also sustained by strong (and sometimes problematic) commitments to the 'passionate', 'creative' and 'self-exploiting' labour commonly associated with highly-committed artists (Banks 2017, McRobbie 2016). Although precarity has always been a characteristic feature of artistic labour, at least to some degree, some critics claim it is increasingly becoming much more widespread, embedded and ingrained (Banks, Gill \& Taylor 2013, Lindstrom 2016, Paying Artists 2014, Throsby \& Zednik 2010).

While the idea of precarity offers a good general descriptor of the conditions of artistic labour, it also has its limits. Significantly, there are two omissions. Firstly, it tends to gloss over some quite marked social differences in the social distribution of precariousness. This is not simply to say that some artists have more stable and better-paid work than others (which is evidently true) but also to suggest that precarity tends to be experienced more acutely by those artists who have come from less advantaged social backgrounds. Working-class artists (who might lack the support of family, spousal or partner finances or inherited wealth), artists from ethnic minority backgrounds (who struggle for recognition and legitimacy in an art world dominated by whiteness), women (long ascribed a subordinate status to male artists) and otherwise minoritised artists (such as artists with disabilities) are evidently much more vulnerable to the challenges imposed by a labour market 
dominated by low pay and unstable and uncertain work (Banks 2017, McRobbie 2016). Secondly, precarity is a rather blunt concept that tends to imply a universal condition of 'temporal poverty' (Hardt \& Negri 2009: 47) -one where all social experience appears dominated by the frenetic demands of an allegedly more speeded-up, unstable and fragmented social world. Often, no other temporalities seem to be pertinent or present (Sharma 2014).

In this article, we show how these two omissions are interlinked-how the neglect of social difference in the distribution of artistic precarity means that we have also neglected some of the temporal complexities of artistic work itself. Our main contention is that if we are to understand artistic labour more fully - and devise means and measures of supporting different kinds of artist in their endeavours - then we might need a better grasp of who artists are, how they work, and what kinds of relation they have to social structures such as those both intimated and contained by conditions of precarity. Thus, we suggest, by researching how artists might be differently positioned in relation to time we not only obtain a more precise understanding of how professional artists' lives are organised, managed and lived, but also a more distinct understanding of precarity itself.

Using illustrative findings from our empirical research with working visual artists in the Midlands of the UK, we propose three schematic ways of thinking about the organisation of time and temporality in routine artistic practice. As we will show, these arise from our own empirical data, backed by our extensive research of the existing literature on art-making, artistic production and cultural and creative work. We name these three temporal contexts as, a) 'the artistic career'; b) 'the time of making art' and c) 'the temporality of the work'. We tentatively propose these as a schematic model that encapsulates much of the temporal conditions of professional art making, in so far it deals with a comprehensive range of phenomena including abstract social structures (the artistic career), the lived reproduction of everyday social practices (the time of making art), and both the subjective and objective materiality of art itself (the temporality of the work). Further, not only do each of these temporalities represent a discrete (but also relational and interacting) time-context with its own distinctive rhythms and dynamics, but they also represent lived conditions where structural relations (and individual senses) of precarity play a significant role.

\section{Methodology and Data}

The empirical data for this study originates from collaboration between the authors and a publicly funded regional network for supporting visual artists, based in the English Midlands. Between 2016 and 2018, the network ran a two-year 
project designed to document the working lives of six of its participating artists. As collaborating researchers, we were invited to design some academic research that would run parallel to the network project. Given our developing interest in temporality in artistic work, and concern that temporality and temporal difference are under-developed aspects of precarity research in (and beyond) artistic work, we proposed a project that would focus specifically on understanding the six artists' perceptions of time in relation to their work, their careers, and the barriers and challenges they experience in the arts sector. The participating artists were drawn from six different towns and cities in the Midlands, and were at different points in their artistic careers. Three men and three women were participant, all but one being UK nationals, with five of the group identified as White, and one as Asian British. Participants were identified as being from either working or middle class backgrounds, and their ages spanned from mid-30s to mid-50s. We thus had a 'spread' of artists from different backgrounds and circumstances if not a statistically representative or fully socially-profiled sample, since the selection of artists was itself already determined by the network who had chosen the participants based on their own (largely aesthetic) and internal criteria, prior to us designing our parallel project.

Our method for data gathering consisted of in-depth interviews. Each participant was interviewed three times: at the beginning of the two-year project, half-way through, and towards the end of the project. The line of questioning was partly pre-determined by our desire to interrogate temporality in art making, yet was also sufficiently open-ended to allow for contingency, and for participants' own unscripted (and often unprompted) descriptions of their working lives to take precedence. Indeed, given the breadth of our topic (general notions of time in work), it was felt that naturalistic interviews eliciting artist's own accounts of their 'everyday working lives' would be sufficient to generate plenty of rich material on temporality, adequate for our theoretical purpose.

The first round of interviews was therefore structured to cover a series of 'general' areas: social and personal background and education, approaches to art making, histories of work and employment, understandings of 'career', and involvement in the network's project. With regards to interview analysis, we followed an inductive, but also theoretically shaped and informed approach, focussed on eliciting coded accounts that spoke variously to the theme of 'time'. Key, or 'top-level' themes were aggregated, sub-themes or nodes allocated, and relations between our themes and nodes reflexively theorised and interrogated, in an attempt to honour the 'dialectical interaction' (Hammersley \& Atkinson 2007: 159) between theory and data necessary for effective qualitative research. Questions for the second round of interviews were more directly interrogative and shaped by some of the key themes around time and temporality that emerged from 
the analysis of the first round of transcripts. Specifically, following the first round of analysis, we were able to identify and codify references to three 'top-level' or primary - but also quite different and distinctive-kinds of temporalities. These we identified as 'the artistic career,' 'the time of making art' and 'the temporality of the work. Based on these three key temporalities, for the second round of interviews we designed a set of more pointed and detailed questions enabling us to explore each of these temporalities, and the relations between them, in turn. Interview transcripts were then coded using categories that corresponded to the three, overlapping temporal contexts that we had identified (including their specific relation to theoretical understandings and artists' own experiences of precarity) which we were able to further question and refine as the process of analysis proceeded. Finally, the third round of interviews was much less structured and had two objectives: collecting participants' final reflections on their involvement in the network project, and expanding or refining points of interest from previous interviews.

In the remainder of this article, we will first define, and then outline findings that detail, the three temporal categories we identified, contextualising them in the existing literature on time and artistic practice. Mainly for reasons of limited space-but also because our analysis is intended to be theoretically suggestive rather than empirically comprehensive-in our empirical analysis we focus on three participants only. This also allows us to discuss in greater detail the three different temporal aspects of artistic careers as experienced by individuals, how these experiences might differ or relate to each other, and how they might be seen to be conditioned by structural factors in the context of an allegedly universal 'precarity'.

\section{Three Temporal Contexts in Artistic Work}

\section{a) The Artistic Career}

An enduring image is that of the artist as an independent and self-realising figure, one who rejects 'base' commercialisation and the demands of the market, in order to pursue a life of creative autonomy (Bourdieu 1993). While masking a more complex reality, the notion of the garret-dwelling artist, eschewing material gain for the rewards of a true and purposeless art has some basis-like all stereotypes -in reality. Most recently Alison Gerber's The Work of Art (2017) has explored the resiliency of a 'vocational' bent in the motivations of contemporary artists - one which prioritises the pursuit of 'art for art's sake', and tends to reject the rhythmic and routinised demands of any art life in service to the market. This ideal has persisted despite significant changes in the workings of the art sector and 
the increased professionalisation of artists in the emergence and development of modern, market societies (see Bain 2005).

Certainly, from the middle of the twentieth century, during a period of strong economic growth and a rapid expansion of the social democratic welfare state, the opportunity and demand for an artistic career extended to the widest spectrum of the UK population (Banks 2017, Frith \& Horne 1987). To have a career as an artist-even if that meant not earning all of one's income from artistic production - became a valid and (for many) obtainable aspiration. From the 1960s the rapid expansion of UK arts Higher Education and the parallel emergence of the 'creative industries' as occupational destinations for the newly-qualified, trained and talented artists has only served to underscore the modern possibilities and potentials of the artistic career, one that might be planned for, nurtured and sustained over time.

We need to acknowledge, however, that while economic growth and a strong(er) social democracy afforded many more people the opportunity to pursue an artistic career over time, not all social groups were able to fully participate (Banks 2017). Further, much current academic and popular commentary has focussed on the more recent decline of creative career opportunity for socially-disadvantaged populations and the entrenchment of artistic precarity for the remainder (Banks 2017, Brook et al 2016). And while the number of arts graduates has increased -and thus boosted numbers of potential entrants to the artistic labour market -the overall number of people in identifiably artistic employment has remained fairly static, while also becoming more part-time, freelance and fragmented, even amidst the wider expansion of creative jobs (where growth has mainly been in computing, technology and PR, advertising and marketing occupations; e.g. see DCMS 2016).

Given these shifts, the 'artistic career' might now be marked by an even greater sense of uncertainty, contingency and multiplicity than previously experienced in the mid-to-late twentieth century. Lingo and Tepper accordingly propose that artistic careers have become more protean, with precarity now 'requiring artists to shift and adapt to diverse opportunities and to work in multiple roles' (Lingo \& Tepper 2012: 341, see also Bennett 2009, Throsby \& Zednik 2011). While a mixed economy of professional activities has long been a feature of artistic labour, this now appears to have become more pronounced in the UK, as elsewhere, and was widely acknowledged by our participants as undercutting notions of any kind of stable foothold in the job market and as strongly affecting understandings of futurity and 'career planning'. 


\section{Culture Unbound}

\section{b) The Time of Making Art}

The idea of 'the time of making art' relates to the time spent in studio or in practice, dedicated to the production of art objects, performances, or other kinds of work. Often imagined to be the most valued and central component of any artist's activity, the time spent making art is imagined to invoke the foundational intensity, passion, desire and ambition one might ideally invest in art work. The most common descriptions of such activity speak to the value inscribed within it; 'the only time I feel alive is when I am painting' famously opined Van Gogh, consolidating a widely-held sense that the time of making art is associated with the immersive, the bodily and the transcendent (see Banks 2014). Yet such intense identifications must also be considered within particular social settings, and so we need also to acknowledge the contested and politicised nature of the complex subjectivities that develop in relation to artistic work. For instance, the application of one's affective 'passion' or 'intensity' might well lead to production of excellent art, but it might equally serve to reinforce the well-established culture of overworking or 'self-exploitation' noted in artistic labour, and often pursued to the detriment of good work, health or well-being (Banks 2017, McRobbie 2016).

Yet it remains that art-making-for many artists-is about the special moments of making. Furthermore, and often, it is not just short-term intensive immersion that is valued but involvement over time, with (for example) Gerber's participants affirming that 'only artistic practice allows for the sort of deep, long-term, open-ended commitment' (2017: 62) that might be required to explore certain aesthetic concerns or issues. Often, the mere act of doing or making art is valued in itself, and not always or necessarily in relation to any eventual output. Gerber's research on artistic careers suggests that artists often find themselves involved in art-making experiences they describe as 'too specific, too esoteric for the marketplace' (ibid) and her findings point to an approach to art-making that is 'led by the work' rather than the frames and temporalities of the market. The focus here is on involved experience, yet also a clear positioning against externally-imposed structures and timelines. In his work on 'making', Tim Ingold notes that we are used to thinking about making in terms of projects (with beginning and end dates, featuring raw materials that get transformed into a prescribed form). But, he proposes, perhaps we should "think of making [...] as a process of growth. This is to place the maker from the outset as a participant in amongst a world of active materials." (2013: 21). From this perspective, the most that the maker can do "is to intervene in worldly processes that are already going on, and which give rise to the forms of the living world that we see all around us" (ibid). This view of making fits within a Bergsonian (2004 [1965]) understanding of time we will be returning to later, one which considers multiple temporalities of being coexisting with each other. From this perspective the maker is not only 
having a distinct, temporal experience, but is also intervening in other ongoing temporal flows and processes in the world.

Our understanding must also be concerned with the less esoteric and sublime aspects of the time of making art. The kinds of routine, everyday practices of making - the mundane assembly of the necessary tools, materials and artefacts, the work of thinking, preparing and planning, the quotidian and repetitive dimensions of art production-are as much part of the temporal economy of art making as any of the 'higher' or more sublime aspects. Art work is as much concerned with what Howard Becker first identified as the "mundane social organizational problems" (Becker 1982: 39) of a practice.

Yet we also note that the time of making art is additionally shaped and challenged by social forces that exist beyond the immediacy of the studio or network. As our own participants revealed, amongst other structural forces, the dynamics of class, gender, ethnicity and age loom large-moulding and detailing the ways in which artists are able to participate and engage in their own practice and wider art worlds. In an economy that appears increasingly given over to precarious working, under conditions driven by the need for 'self-resourcing', and 'project' and 'portfolio' career-making, then an obvious question arises as to who is able to afford the opportunity or luxury to participate in the 'time of making art' at all?

\section{c) The Temporality of the Work}

The temporal dimensions of the work of art itself-the ways in which a time-based aesthetic, symbolism or consciousness is conceived or materialised-represented a further way in which our sample of artists understood time in the context of practice. There is, of course, a historical multiplicity of ways in which temporal concerns have found their way into art works, often responding to the social, political and technological conditions of a particular era. For instance, the nineteenth century impressionists pioneered an aesthetic style of quick-painted strokes in seeking to capture the fleeting and evanescent moments of the new Modernity (Dombrowski 2013). From the mid-twentieth century the growing affordances of film, video and photographic technologies allowed for "an unprecedented degree of control over moving images" (Lütticken 2010: 25), and an emergent obsession with time-based visual art (Lee 2004). For example, new experiments in re-arranging and 'killing' time in the 1960's (e.g. Warhol's films), were followed in the 1970's by an increased use of stills (an attempt to 'freeze time'), and, in the 1990s, by film and video art that revelled in slowness, as a critique of the tyranny of speed in contemporary visual and consumer culture (Lütticken 2010). Contemporary genres have since come to embrace multiple chronologies in their conceptual and material formations. Writing about Afrofuturism and the 
work of contemporary African visual artists such as Georges Adeagbo and Meshac Gaba, Kodwo Eshun has argued that "[t]o establish the historical character of black culture [...] it has been necessary to assemble countermemories that contest the colonial archive", and that "the vigilance that is necessary to indict imperial modernity must be extended into the field of the future" (Eshun 2003: 288).

In addition to the ways in which artists deal with time in their work, there is also the issue of works of art in time. Étienne Souriau (1949) first challenged the idea that the visual arts are 'arts of space' and the phonetic and cinematic arts are 'arts of time'. He argued that the idea that a painting can be seen in its entirety in an instant is false, and that contemplation of a work of art (not least by audiences) unfolds and changes through time. More recently, and further connecting the work of art with its reception, Nagel and Wood (2010) argued that works of art always inhabit plural temporalities. The artwork is made by someone at a particular point in time, but refers to ideas or events that often preceded that moment, or point to an imagined future. The work-and the perceptions of it - can also transform over time and accumulate different meanings, as a developing and evolving 'aura' in the terms proposed by Benjamin (2008[1936]).

\section{Three Artists at Work in Time}

Thus far, we have drawn from our empirical work and from a range of disciplinary perspectives on the relationship between time and artistic practice to outline three schematic ways of looking at time in the working lives of artists. However, these different temporalities could also be said to be part of the same experiential whole. Henri Bergson (2004 [1965]) famously argued that we can experience different forms of time, or what he terms 'flows', simultaneously. If we adopt the basic premise of a Bergsonian approach, we can talk about the 'artistic career', 'the time of making art' and 'the temporality of the work' as mutually imbricated and coexisting.

In what follows, we report on the more detailed testimonies and experiences of three artists in order to illustrate this simultaneous co-existence of the three different temporal facets of artistic work. ${ }^{1}$ The three visual artists in this section have different backgrounds and trajectories in the arts, and sit structurally positioned to precarity in different ways. Their testimonies expose the ways in which artists understand and experience the three different temporal aspects of their working lives as outlined in the previous section.

\section{Adam}

Adam is a painter. He is a White male, in his early forties, brought up in a professional middle-class family, who began making art at a young age. He went 
to art school after completing his secondary education, and following graduation rapidly achieved commercial success, showing his work in galleries and making a comparatively well-paid living by selling his paintings. Eventually, after a few years of producing art for metropolitan and highly-commercial art markets, he took a step back, and began to concentrate on other process-oriented, long-term projects. To compensate for a fall in income, Adam obtained a part-time job as a lecturer at a local university which offered him a degree of stability and security, away from the full-time pressures of selling art-his 'artistic career' therefore has transitioned somewhat since its early, high-profile success. When we asked Adam about his understanding of 'success' he said that if he were responding with his 'old hat on', success was about pursuing an idealised and individualised career trajectory in the commercial art world:

Oh god! If I was to have my old hat on, where it was about career trajectory and being successful, then I've been in some big shows, and I've been in a show in the Saatchi gallery, I've been in the Royal Academy summer show, the main ones probably. The John Moores painting show which was in 2008 . That probably did kick-start my painting career in a way.

However, Adam stated he is not 'riding that wave' anymore. This kind of fast-paced, commercially-oriented working pattern he found tiring, difficult to sustain and was negatively affecting his personal relationships. He described his current pattern as more 'sustainable', and claimed he is now trying to measure success in his own more varied terms-outside of the immediate demands and dictates of the commercial and high-profile art market.

For Adam, the relative stability of a part-time teaching position allows for a longer-term planning in artistic production:

I think the part-time job allows me that space to allow my practice to develop in the way I want it to develop, with a sort of long-term [outlook] rather than short term [one], e.g. the next show, or the next exhibition. [...] I'm looking also two or three years into the future, rather than two or three months into the future. So that's healthier, for me that's good.

The combination of a smaller (but more stable) income and a move away from the freneticism of high-profile art selling also resulted in a reconfiguration of Adam's making processes, one that now allows him to also prioritise the time of making art': 
I'm so used to getting by with very little money that time for me is what's important, time to make those things [...] And now it's like 'ok, I've got that'. I've got this time to do research to make this new body of work, and it feels like I'm empowered with the time now. The past has often been about - particularly when I was completely freelance - there was lot of pressure to make sales, make a particular type of work. Yeah, it's a different. I try not to be complacent basically with that time, with how I use that.

In the past, the context for Adam's art making was dictated externally (reacting to the demands of galleries and commissioners, as he put it), yet his work now feels more like an open-ended 'project without a particular end point, which hopefully will [be reflected] in my work. One of Adam's current long-term, open-ended projects involves the production of his own painting materials. This project has meant that he has had to adapt his working patterns to new, slower timeframes than those he was used to (for instance the harvesting times for the flax he uses for making his own canvases). Thus, within this now more relaxed and exploratory temporal phase, Adam was able to better reflect on what he called the 'space of making' - a productive intersection of space and time that enables more intensive art-making and immersive experiences:

I think it's a strange kind of qualitative, meditative space. The painting, $[\ldots]$ you let strange influences come in and ideas come in, and thoughts come in while you make your work. I don't know it feels like a feedback, feels like a loop. And you enter that place, like returning home or something. It's like a strange place you go back and 'Oh, I've been here' [...] within [that space] I can actually work quite quickly and quite frantic. Because once I'm in, in this space or flow of work, I find it quite easy to just get on with the work. When I've got a plan, an idea of what I'm doing, I will just do it. And that can be really productive.

With regards to the 'temporality of the work' Adam reflected on how much of his painting is inspired by traditional and linear depictions of 'nature' and 'landscape', but now the sources, as well as the form and content of his work, were becoming more diverse, multi-faceted and experimental. Indeed-and mirroring Souriau's (1949: 294) view on visual work as capable of generating spatial-temporal universes-Adam reported how he'd recently begun to seek inspiration from diverse sources such as quantum physics, but also the science fiction literature he read as a child, recast into new painted explorations of 'failed utopias' and other non-naturalistic landscapes and futures. In his own words: 'the narrative within 
the work, the images in the work are at times romantic but also inspired by future, post-apocalyptic sci-fi narratives. His paintings therefore reference past, present and future aesthetic imaginaries, while also connecting with his own personal past. Indeed, Adam expressed how his painting is also strongly influenced by an interest in the idea of time itself:

I'm interested in geological time, and ways of perceiving time that are non-linear. I do that through the painting process, particularly at a landscape. So I wanna see a landscape that's in flux, that's in the process of either being created or being destroyed. And I'm interested in how paint, and washes and layers can do that.

In other words, Adam's chosen aesthetic forms and techniques are a reflection of his intention of engaging with the idea of time in thematic content, where a mode of working - washes and layers-foregrounds a particular temporality and rhythm in the imagination and conceptual making. Furthermore, his recent focus on the deep(er) materiality of his work (such as him growing his own canvas materials) has added other temporal dimensions to this creative process, not only adding layers of meaning to the representation of landscape (now that he is himself involved in the process of turning the landscape into a painting), but also completely changing the production timescale of the work. In the act of making, Adam is interacting with the flows and the "becoming of his materials" (Ingold 2013: 31).

\section{Nila}

Nila is a British Asian artist, of Indian heritage, from a working-class background, in her early forties. Compared to Adam, her route into art was much less straightforward; she studied non-arts academic subjects and worked in a number of different jobs and industry sectors prior to becoming an artist. She is a multi-media visual artist (principally photography and film-making and more recently textile), and her practice has a strong element of interaction and engagement; so while she has a line of work that she describes as her 'own', she also has a social enterprise through which she works on community and socially-engaged art projects, particularly working with working-class women, often drawn from ethnic minority groups. This shared commitment to both personal and more community-oriented work explained something of Nila's temporally diverse patterns of artistic work. Having finally established herself as a professional artist in her thirties, she reflected on the barriers often faced by working class and ethnic minority artists in pursuing artistic careers, and particularly the obstacles offered by the education system, commenting, in typical 
example, that 'the education system for working class people doesn't provide you with what you need to be successful in the arts and cultural industry'. Nila's view that the system's 'odds were stacked against her' reflected a well-established critical concern that the economic and cultural capitals required to even enter into-let alone be successful within-a precarious art world are less readily available to socially-disadvantaged or minoritised artists.

Nila's perception of success in an 'artistic career' was twofold: on the one hand, she judged success in terms of conventional gains such as commissions, awards and prestigious residencies, while on the other hand, she related success to obtaining understanding and acceptance from her family-a benchmark for personal achievement that has often been noted to be less of an ambition (or a burden) for middle class and White artists (Saha 2018). She also judged success in terms of the personal and social 'connectivity' that her art had on the people and communities she works with-what could be termed a 'relational' approach to art-making.

When asked about time and work, and the trade-off between what we might term heteronomous production (to serve pecuniary necessity) and obtaining time for more self-directed, autonomous production, Nila expressed a valuing of time akin to Adam's:

I have sort of accepted not having a lot of things, and it's become the norm. It's that trade-off between having freedom of time, as in, you know, where do I spend my days, to, not having stuff. That trade-off between time and what I call slavery I suppose, having to be somewhere all the time.

Like Adam, Nila understood 'the time of making art' to be in tension with the time demands of purely commercial production. Seeking to secure the freedom to pursue her practice in a more disinterested and free-flowing manner, Nila referred to her current chosen working pattern:

I don't wanna give myself the pressure of working towards an exhibition. I'm just really enjoying the kind of exploration of ideas at the moment. It's really nice to not have the pressure of thinking about it.

However, the ambivalence of this position was also often felt by Nila, and she offered that the dream was 'to have the flexibility to continue to be an artist, yet have some sort of security at the same time. Thus, Nila's pattern of work tended to be marked by a mixture of (fairly small) public or commercial personal commissions, some community arts work organised thorough her own social 
enterprise, and intermittent other one-off opportunities, such as working with local HE organisations. This enabled her to earn a basic, subsistence income ('less than the minimum wage'), sufficient to allow her to devote the fullest time to her practice - even if this meant financial uncertainties or difficulties from time to time. Nila's more social or community oriented artistic work was, however, marked by a different rhythm and tempo, partly because it was often commissioned, scheduled and time-bound. Yet, as a composite, her time was marked generally by its own irregular rhythms and chronologies, reflective of an active but often unpredictable and non-linear working pattern:

There's no way I could even begin to tell you how much time I allocate to [different activities] [...] this is the thing about being a freelancer you know. I do things as they need to be done.

But it was precisely this unpredictability, and lack of stable anchoring to either fixed employment or a solitary mode of working, that helped support the richness and depth of the 'temporality of the work' contained in Nila's art. The dominant themes of her art work - the effects of colonialism, capitalism and patriarchy on communities, and on marginal and vulnerable persons in different social and geographical locations-are strongly informed by the extensive time she chose to devote to personal research, community and collaborative engagement (and community co-production), so necessitating a continuous demand for travel, interlocution and exchange with others, and a constant scoping of different intellectual and cultural horizons:

So a lot of what I look at is the effects of industrialisation, the effects of labour on women and Indian people [and] how trade and migration and imperialism affected migrant people, but also how it's affected their sense of identity and sense of place in the world [...] Time feels like a construct that I'm kind of fighting against. So as you can see there's a lot of things there that I'm trying to make sense of.

To give an illustrative example, some of Nila's recent work has been motivated by the rapid changes in lifestyle she witnessed when visiting family in India, and a need to visually capture such changes. Other work has been exploring the temporalities of making in relation to local (Midlands) textile production, and the effects of industrialisation on people's understandings of traditional art and craft. Other work has explored industrial decline in ex-mining towns in the Midlands. Her work has multifarious influences, and stylistically and aesthetically often draws upon, collages or collapses time in its making, as she explained: 
....you are just picking bits out of nowhere all the time. Like I said, geographically, the ideas are coming from Russia, 1920s. Or 16th century India, and you know, I'm kind of also looking at the future as well.

In eclectic and dynamic fashion, Nila's work brings together references and materials from different parts of the world and different moments in time, and combines them into a multi-media, relational kind of artistic practice. She very much saw her role as that of a 'connecting' agent, identifying and generating links between people, traditions, histories, temporalities and places-while navigating her own precarious traversals between professional survival, subsistence and security.

\section{Emma}

Emma is a painter and conceptual visual artist and a mother. After spending some years combining the raising of her son with working in non-arts jobs, including nursing, she decided to return to education as a mature student in order to undertake a part-time degree in fine art. Subsequently, with family support, she decided that she 'would give up my paid job to just do art'. Now in her fifties, she works as an artist and as an arts educator, and combines this with caring responsibilities at home, as well as often caring for her parents. Emma's reflections pointed to a different kind of precarity, that of time-poor carers trying to juggle multiple responsibilities, and uncovered some of the structural disadvantages faced by mature (especially mature women) artists and artists who are carers. Her experiences of time management illustrate how the time of making is affected by external factors, but also, how externally-imposed structures can also be challenged and transformed through relational temporalities.

In respect of the 'artistic career' two things that Emma was quick to identify when asked about her experience in the arts sector were the barriers of age and gender:

I suppose it happens across the board in all careers for all women. When you reach fifty it's that period when you're at a level where you go for senior jobs. But you're menopausal, you've got teenagers probably, your parents are getting old. It's a difficult time. So I think age is a factor that brings its own challenges and barriers.

Emma went on to explain that her age and her caring responsibilities prevent her, for instance, from attending evening events such as exhibition previews and artist talks, which are important spaces for networking. This, she said, is a 
barrier for her career development, an experience that fits within a growing body of work that points to the challenges women face when embarking on artistic careers (McRobbie 2016, Miller 2016) - and one that highlights some of the social differences contained within the assumed context of a universal experience of precarity.

When asked about her working patterns (or 'time of making art'), Emma explained:

It's all broken up, and grabbing bits of time here and there. Ideally I would have two full days of working in my paid work, and then concentrate [the other] days on making my own art. Although ideally, five days making art!

The ideal of preserving dedicated time for open-ended, autonomous work was something referred to by all our artists. Emma aspired to this condition, but was only able to obtain it in a more fragmented way than that suggested by Adam or Nila:

At the moment, I do feel that there's quite a lot of things I haven't seen through [...] I think it's ok that I start things, I'm not really sure, put it to one side, work on something else and then come back to that when I've thought more about it. So my process is a bit all over the place. Unless if I have a definite project to do, an exhibition or an event to organise [...] I plan well when something is in the immediate future.

Emma's work pattern is therefore responsive, but also quite reactive; her approach to work and time is more mechanical when responding to external impositions, and less restricted and non-linear when she is not. Yet in terms of the overall 'progression' of her work and her career, Emma's personal circumstances meant that she was perhaps less able to focus on working consistently and incrementally on projects in the way that Adam or Nila were able to describe. Emma suggested that she often starts projects and then gets side-tracked by other or unforeseen things-including her caring responsibilities-returning later to old ideas or picking up on projects she had put aside. At the same time, however, she identified a particular pressure she felt to develop a clearer sense of conventional progression in her career:

I was thinking about being an older artist. And, so at this time in my life is when I guess, I'm sort of established as an artist, I know where I'm going, I know what I'm doing. But there's these sort of unseen, unheard 
pressures to be seen to progress, to achieve more, to exhibit more. To raise your profile more. As well as internal pressures. I want to do that myself, I want to progress, I want to do stuff.

Emma's current main project is a participatory one for which people are invited to submit stories and reflections about their relationship with their mother. Her work is relational in that it draws from the experiences of others, and it is also concerned directly with temporality, as it explores people's memories and past and present experiences, as well has having a marked autobiographical element centred around Emma's own experience of motherhood and how this has changed (and changed her) over time. The project emerged during a one-year residency, but ended up extending beyond its original timeframe. She explained:

At the end of the residency, even though I had exhibited it in different places, it wasn't really resolved, or I felt it could go on further. People kept asking me about it, so it's been kind of traveling the country, to different locations. And it continues to interest me, continues to interest other people. It doesn't feel like it's got an end. So when I started I did think it was time limited, I thought it was gonna be just for this year. But actually, that was maybe three years ago? And it's just carried on. [...] to me this interactive, participatory involvement of so many different people is the art really, and I don't know if it does need a final thing to mark the end of it.

In this project, Emma has abandoned a mechanical temporality (a pre-determined and time-bound production) for a relational one. In other words, the progression of the project has come to be determined by other people's involvement with it rather than the structures and timeframes of the cultural institutions Emma has worked with: as long as people are participating, the project carries on. However, while Emma is happy to be able to continue the project, its open-ended nature raises the challenge of sustaining it (and herself) financially. Now that the project is not attached to a residency or grant, Emma's work on it is mostly unpaid and without allocated resource, and this has limited the way in which she is able to continue with its development.

\section{Conclusion}

The aim of this article has been to explore the complex temporalities of artistic work, proposing a framework for better understanding temporal experiences in artistic work and using this to show, through indicative example, how different 
visual artists might sit in relation to what is often assumed to be the universal condition of 'high speed' and 'time-poor' precarity. We have sought to show how precarity is not a singular condition, but a more complex and relational force, one that contains many temporally-structured ways of being and living as a professional artist. While precarity is the lens through which we have become accustomed to look at the experiences of artists as workers, and is indeed an important perspective, some of the dominant associations of precarity can serve to obfuscate important nuances about the different temporal aspects of artists' working lives. A more holistic approach to the place of time in artistic work-exemplified here in the concepts of 'the artistic career', the 'time of making art' and the 'temporality of the work'-therefore, can open up new avenues for understanding artists' experiences and the more detailed contours of their ordinary working lives, under conditions of an assumedly accelerated and time-poor precarity.

Each of our artists were 'precarious' to different degrees, or precarious in different ways, and within this precarity, exhibited different levels of agency in the choices they could make about how they spend their time. By withdrawing from the precarious (but well-paid) pressures and demands of maintaining 'success' in the commercial art world, Adam was able to achieve a greater stability and security, one that was less well-remunerated, but more anchored in a rhythm that opened up the possibilities of making art according to his own autonomous tempo, and thinking about time in the content of his art, in new ways. Nila existed in a more recognisable state of social and economic precarity—as a working class and ethnic minority woman artist, seeking professional and familial acceptance, while eking out a subsistence living-yet her condition of precarity was also itself in some ways generative and necessary since it afforded opportunity for a more dedicated 'time of making art', and investment towards a particular and unique 'temporality of the work'. Emma's more contained freedoms were strongly shaped by her caring responsibilities and a sense of being at a more precarious career stage, as a 'late' developer in professional terms. The restrictions of age and gender combined to challenge any easy assumption of a free and unfettered career trajectory in the art world. Yet the complex rhythm of her combined life of work, motherhood and care was able to inspire and exert positive influence in the 'temporality of the work', as her project continued to garner creative success.

As well as differences, each account presented similarities-and not just the shared similarity of working in a precarious creative profession. All our artists' responses pointed to the possibility of multiple and changing understandings of success and achievements in 'the artistic career', including linear and progressive perspectives tied to traditional landmarks of progression and recognition, alongside more holistic, personal, and relational perspectives. Our wider set of interviews also revealed how structural factors always seem to shape and constraint 
(as well as enable) the way artists are able to dedicate to the 'time of making art'. Some professional artists, particularly those with stable incomes or arts-related jobs might tend to have a clearer idea of their future projects and career trajectory. Others (such as working class artists, ethnic minority artists, or those with caring responsibilities) cannot necessarily plan as far in advance, and often feel they are not in a position to do so. If we also look at artists' statements on their day-to-day activities and experiences, they reveal that most artists need unbound time to create, but also need to work, to different extents, within social and institutional structures that are external to art, and the time of unbound making.

The manner in which the artists spoke about time in relation to their work suggests that the different temporalities we have identified are reflexively negotiated. The way in which this reflexive negotiation takes place is, in turn, enabled and constrained by the structural position of artists (i.e. class, gender, age, ethnicity). In all cases, however, we could argue that time and the reflexive negotiation between time and other elements (such as financial compensation, stability, notions of success) is such a defining trait of the lives of artists working under precarity that it becomes constitutive of artists' identities.

Our main claim therefore is that, within precarity, artists inhabit multiple, simultaneous temporalities, which correspond to different aspects of their commitment to live and work as an artist. These temporalities can structure and shape the conditions of possibility in restrictive ways-but can also be helpful in generating different aspects of the work, from moments of making to thinking about future projects. For us, understanding these time-based nuances of precarity - in terms of the 'career', the time of making and the temporal qualities of the work-is one way through which we might obtain better understandings of the conditions of artistic labour today.

The wider contribution we hope to make with this study is twofold. First, we believe that the framework we propose for understanding the different facets of artistic work in relation to time-while exploratory and speculative-might prove useful for generating further, or more nuanced theoretical and empirical understandings of artistic work under precarity. And second, by exposing the temporal (and therefore also material) challenges faced by artists in sustaining both their careers and their day-to-day time for making art, the findings from our empirical research expose the need for enabling and widening employment opportunity, seeking to establish more stable, longer-term support for artists, confirming in this way the arguments put forward by other recent reports and studies on the problems faced by working artists today (e.g. CAMEo 2019, Paying Artists 2014, Mahon et al 2018). In other words, this article is a call for policies that address precarity in the arts sector, as well as a call for research on artistic labour and precarity that is nuanced enough to properly support such policy efforts. 
Paula Serafini is Research Associate at the CAMEo Research Institute for Cultural and Media Economies at the University of Leicester. Her research interests include cultural production and cultural work, art and politics, and environmental politics. She is author of Performance Action: The Politics of Art Activism (2018) and co-editor of artWORK: Art, Labour and Activism (2017). E-mail: paula. serafini@leicester.ac.uk

Mark Banks is Professor in the School of Culture and Creative Arts at the University of Glasgow. He writes about cultural industries, work and cultural policy. He is the author of The Politics of Cultural Work (2007) and Creative Justice: Cultural Industries, Work and Inequality (2017). E-mail: Mark.Banks@glasgow. ac.uk

\section{Notes}

1 Participants' names are pseudonyms.

\section{References}

Bain, Alison (2005): "Constructing an artistic identity", Work, Employment and Society 19:1, 25-46. https://doi.org/10.1177/0950017005051280

Bain, Alison \& Maclean, Heather (2013): "The Artistic Precariat", Cambridge Journal of Regions, Economy and Society 6:1, 93-111. https://doi.org/10.1093/cjres/ $\underline{\mathrm{rss} 020}$

Banks, Mark (2014): "Being in the Zone of Cultural Work", Culture Unbound 6, 241-262.

Banks, Mark (2017): Creative Justice: Cultural Industries, Work and Inequality, London: Rowan and Littlefield International.

Banks, Mark; Gill, Rosalind \& Taylor, Stephanie (2013): "Introduction: Cultural Work, Time and Trajectory", M. Banks; R. Gill \& S. Taylor (eds.) Theorizing Cultural Work: Labour, Continuity and Change in the Cultural and Creative Industries, London: Routledge, 1-16.

Becker, Howard (1982): Art Worlds, Berkeley: University of California Press.

Benjamin, Walter (2008 [1936]): The Work of Art in the Age of Mechanical Reproduction, translated by J.A. Underwood, London: Penguin.

Bennett, Dawn (2009): "Academy and the Real World Developing realistic notions of career in the performing arts", Arts \& Humanities in Higher Education 8:3, 309-327. https://doi.org/10.1177/1474022209339953

Bergson, Henri (2004): Duration and Simultaneity, Indianapolis, New York and Kansas City: The Bobbs-Merrill Company, Inc.

Bourdieu, Pierre (1993): The Field of Cultural Production: Essays on Art and Literature, New York: Columbia University Press.

Brook, Orian, O’Brien, David \& Taylor, Mark (2016): Panic! Social Class, Taste and Inequalities in the Cultural Industries, http://createlondon.org/wp-content/ uploads/2018/04/Panic-Social-Class-Taste-and-Inequalities-in-the-Creative-Industries1.pdf 


\section{Culture Unbound}

Journal of Current Cultural Research

CAMEo (2019): "It Takes a Region to Raise an Artist: Understanding the East Midlands" Visual Arts Economy, CAMEo Research Institute: Leicester.

DCMS (2016): DCMS Economic Estimates, London: DCMS. https://www.gov.uk/ government/collections/dcms-sectors-economic-estimates

de Peuter, Greig (2014): "Beyond the model worker: Surveying a creative precariat", Culture Unbound 6, 263-284.

Dombrowski, André (2013): "Painting Time: Impressionism and the Modern Temporal Order", Institute for Advanced Studies, https://ias.edu/ideas/2013/dombrowski-time

Eikhof, Doris \& Warhurst, Chris (2013): "The Promised Land: Why Social Inequalities are Systemic in the Cultural Industries", Employee Relations 35:5, 495-508. https://doi.org/10.1108/ER-08-2012-0061

Eshun. Kodwo (2003): "Further Considerations of Afrofuturism", CR: The New Centennial Review 3(2), 287-302.

Frith, Simon \& Horne, Howard (1987): Art into Pop, London: Methuen.

Gerber, Alison (2017): The Work of Art: Value in Creative Carriers. Stanford: Stanford University Press.

Gill, Rosalind \& Pratt, Andy (2008): "In the social factory? Immaterial labour, precariousness and cultural work", Theory, Culture and Society, 25:7-8, 1-30. https:// doi.org/10.1177/0263276408097794

Hammersley, Martin \& Atkinson, Paul (2007): Ethnography. Principles in practice (Third edition). London \& New York: Routledge.

Hardt, Michael \& Negri, Antonio (2009): Commonwealth, Cambridge: Harvard Univeristy Press.

Hewison, Kevin (2016) "Precarious Work”, S. Edgell et al (eds.) The Sage Handbook of Sociology of Work and Employment, London: Sage, 428-443.

Ingold, Tim (2013): Making: Anthropology, archaeology, art and architecture, London \& New York: Routledge.

Kalleberg, Arne (2009) "Precarious Work, Insecure Workers: Employment Relations in Transition', American Sociological Review, 74: 1, 1-22

Lee, Pamela (2004): Chronophobia: On Time in the Arts in the 1960s, Cambridge, MA: MIT Press.

Lindström, Sofia (2016): “Artists and Multiple Job Holding-Breadwinning Work as Mediating Between Bohemian and Entrepreneurial Identities and Behavior", Nordic Journal of Working Life Studies, 6: 3, 43-58.

Lingo, Elizabeth L. \& Tepper, Steven J. (2013): "Looking Back, Looking Forward: Arts-Based Careers and Creative Work", Work and Occupations, 40:40, 337-363. https://doi.org/10.1177/0730888413505229

Lütticken, Sven (2010): “Transforming Time”, Grey Room, 41, 24-47. https://doi. org/10.1162/GREY a 00009

Mahon, Marie; McGrath Brian; Ó Laoire, Lillis \& Collins, Patrick (2018): "Artists as workers in the rural; precarious livelihoods, sustaining rural futures", Journal of Rural Studies, 63: 271-279.

McRobbie, Angela (2016): Be Creative: Making a Living in the New Culture Industries, Cambridge: Polity.

Miller, Diana (2016): "Gender and the Artist Archetype: Understanding Gender Inequality in Artistic Careers", Sociology Compass 10:2, 119-131. https://doi. org/10.1111/soc4.12350

Nagel, Alexander \& Wood, Christopher (2010): Anachronic Renaissance, New York: Zone Books.

Neilson, Brett \& Rossiter, Ned (2005): "From Precarity to Precariousness and Back Again: Labour, Life and Unstable Networks", The Fibreculture Journal, 5. Available at http://five.fibreculturejournal.org/fcj-022-from-precarity-to-precariousnessand-back-again-labour-life-and-unstable-networks/ 
Paying Artists (2014): How We Got Here http://www.payingartists.org.uk/wp-content/ uploads/2016/07/How-We-Got-Here-Culmination-of-Paying-Artists-Consultation-Process-2014-16.pdf

Pasquinelli, Cecilia \& Sjöholm, Jenny (2015): “Art and resilience: The spatial practices of making a resilient artistic career in London", City, Culture and Society, 6: $75-81$.

Prosser, Thomas (2016) "Dualization or liberalization? Investigating precarious work in eight European countries", Work, Employment and Society, 30: 6, 949-965.

Saha, Anamik (2018): Race and the Cultural Industries, Cambridge: Polity.

Sharma, Sarah (2014): In the Meantime: Temporality and Cultural Politics, Durham NC: Duke University Press.

Souriau, Étienne (1949): "Time in the Plastic Arts", The Journal of Aesthetics and Art Criticism 7:4, 294-307.

Standing, Guy (2011): The Precariat: The New Dangerous Class, London: Bloomsbury.

Throsby, David \& Zednik, Anita (2011): "Multiple job-holding and artistic careers: some empirical evidence", Cultural Trends, 20:1, 9-24. https://doi.org/10.1080/09 548963.2011.540809

Vosko, Leah (2000): Temporary Work: The Gendered Rise of a Precarious Employment Relationship. Toronto: Univeristy of Toronto Press. 